\title{
Underground COVID-19 Home Hospitals for Haredim: Non-Compliance or a Culturally Adapted Alternative to Public Hospitalization?
}

\author{
Gillie Gabay ${ }^{1}$ (D) Mahdi Tarabeih ${ }^{2}$ (D)
}

Accepted: 21 August 2021 / Published online: 2 September 2021

(C) The Author(s), under exclusive licence to Springer Science+Business Media, LLC, part of Springer Nature 2021

\begin{abstract}
This thematic study analyzed the experiences of Jewish Haredi (Lithuanian) patients in underground home hospitals during the second wave of COVID-19 in Israel. This minority comprises $12.6 \%$ of the Israeli population. Participants were 30 members of this hidden population, ages 59-78. Haredi complied with community directives rather than with the national directive of hospitalizing COVID-19 patient only at public hospitals. Compliance with community directives was driven by a distrust in health authorities and clinicians at public hospitals; by the preference of patientcentered care, a desired approach of care that public hospitals fail to implement; by the need to sustain beliefs, values, and traditions; by community leadership; and by the need to conserve political power. While health authorities view underground home hospitals as demonstrating non-compliance with the national directive, Haredi leaders view underground home hospitals as demonstrating a self-sufficient, patient-centered care alternative to public hospitalizations. Considering the benefits of patient-centered care and the growth of the multi-cultural global landscape, we call upon health authorities to explore the accommodation of patient-centered care for COVID-19 patients and the designing of an adaptive multi-cultural policy that address multi-cultural aspects of religious minorities as key to health promotion. We propose ways to implement multi-cultural policies.
\end{abstract}

Keywords COVID-19 $\cdot$ Health-policy $\cdot$ Government health policy $\cdot$ Noncompliance $\cdot$ Religious minority $\cdot$ Religious polarization $\cdot$ Trust

Gillie Gabay

gillie.gabay@gmail.com

Mahdi Tarabeih

Tarabeih1969@gmail.com

1 School of Multi-Disciplinary Studies, Achva Academic College, 7980400 Arugot, Israel

2 Faculty of Nursing, Tel-Aviv-Jaffa Academic College, Tel-Aviv, Israel 


\section{Introduction}

Public compliance with health policies depends on public trust in governments (Bargain \& Aminjonov, 2020; Chaudhry et al., 2020). Members of religious minorities demonstrate lower compliance than do others, yet the stringent enforcement of health policies among minorities may lead to higher non-compliance (Allcott et al., 2020; Laufs \& Waseem, 2020; Patel et al., 2020). Social unrest has been growing among minority populations worldwide, further lowering trust in health authorities (Algan et al., 2020). The trust of the Jewish Haredi minority in the Israeli health authorities sank to a new low during the COVID-19 pandemic (Herman \& Orr, 2020; Ripoll, 2020).

The national directive in Israel subjects all medical activities in hospitals to regulation by the health authority. The national emergency directive mandates that all citizens with severe symptoms indicating COVID-19 be hospitalized in supervised public hospitals. Recently, non-compliance with this directive among the Haredi minority was exposed. The Haredi [plural: Haredim] stream in Judaism refers to what has also been called ultra-Orthodox Judaism and includes both Hasidic and Lithuanian sub-groups. Since the second wave of COVID-19, Haredi COVID-19 patients have been hospitalized in underground home hospitals (hereinafter: UHHs), far from the eyes of the regulator and without its supervision. Qualitative studies on religious minorities during pandemics are scant (Ripoll \& Jones, 2019; WilkinsLaflamme, 2016). This study explores the lived experiences of Haredi COVID-19 patients in the UHH. The non-compliance with the national directive regarding hospitalization in public hospitals may emerge from strong compliance with community directives, which may be particularly relevant in the present multi-cultural global society. UHH entail patient-centered care. Understanding the lived experiences of this unique religious minority and its leaders during a pandemic may broaden the lens and assist health authorities to implement more effective policies across population groups in the world.

\section{Patient-Centered Care: The Theoretical Framework}

Patient-centered care (PCC) has moved to the forefront of healthcare and is the advocated strategy (Lusk \& Fater, 2013). While the biomedical model focuses on the disease in the patient's body, the PCC model focuses on understanding the patient as an individual (Epstein \& Street, 2011). The limitations of the conventional 'biomedical model' lead to the emergence of patient-centered care (Kitson et al., 2013b). The PCC approach places each patient at the center of the healthcare system recognizing the patient's physical, psychological, and social needs (Voshaar et al., 2015). PCC encompasses respect for each patient's values and preferences towards wellbeing (Delaney, 2018; Lusk \& Fater, 2013). PCC moves beyond traditional paternalistic care to flexible health care entailing a shift away from fragmented institution-centered care to integrated, patient-tailored care that aims to meet patient needs (Cheah, 2001). PCC delivers more holistic care; enhances communication skills between relatives, patients and healthcare providers; shifts emphasis from body care to total 
care; integrates the care; informs the patient on treatment and care; provides physical comfort and emotional support; involves patients and families in decision-making; and ensures transition and continuity of patient care (Kitson et al., 2013a). PCC considers the patient's point of view and circumstances and is characterized by high responsiveness to patient needs and preferences and using the patient's informed wishes to guide activity (Jarrar et al., 2019). PCC views illness as impacting the patient's well-being and seeks to provide reassurance, support and comfort (Rathert et al., 2013). PCC is associated with higher patient safety, higher quality of care, better clinical outcomes, higher patient satisfaction, higher life quality, higher wellbeing, better healing and less suffering among patients (Jarrar et al., 2019; Rathert et al., 2013; Venhuizen, 2019). While PCC is the preferred strategic approach, public hospitals are far from achieving it (Kuluski et al., 2016; Stadler, 2007).

\section{The Haredi Jewish Minority}

A religion is "a unified system of beliefs and practices relative to sacred things, that set apart beliefs and practices that unite into one single moral community" (Durkheim, 1995). Judaism is a religion of "lineal descent", i.e., a person is Jewish because that person is born to a Jewish mother. As a consequence, a strong collective identity is created, whose culture downplays the importance of religious dogma and focuses on religious behavior. Religious behavior does not necessarily express internal beliefs so there is much latitude regarding what constitutes appropriate religious beliefs. Collectivism has been defined as the reliance on obligation and overcoming one's own desires for the good of the collective (Cohen and Hill, 2007). In this sense, Haredi Jewish religious is a collectivistic culture and its members' religious behavior is tightly regulated through tradition that confers identity and creates belonging.

The Haredi Jewish minority in Israel comprises $12.6 \%$ of the population and is a well-defined, discrete minority organized in contiguous voluntary communities, set within a modern surrounding secular society on which it depends and with which it interrelates (Cohener \& Malach, 2020; Friedman, 1991). This minority is characterized by large families living in densely populated areas with higher rates of comorbidity, putting them at high-risk for severe consequences of COVID-19 and elevated mortality rates (Dorn et al., 2020; Pirutinsky et al., 2020). According to the National Social Insurance Institute for 2018, the income of $18 \%$ of families in Israel is below the poverty line. While the poverty rate in the non-Orthodox Jewish population is $11 \%$, the poverty rate in the Haredi Jewish population is $42 \%$ due to the large families, the low rate of working men, and the relatively low wages of those who do work (Cahner \& Malach, 2020).

This minority has an annual growth rate of $4.2 \%$, the highest growth rate in developed countries and in Israel. This rate is attributed to the young age of marriage, the high fertility rates, and the modern medical and living conditions. In Israel, this population is expected to reach $16 \%$ of the total population in 2030 . If this growth trend continues, the Haredi population will double every 16 years, whereas the entire Israeli population will double every 37 years, and the Jewish non-Orthodox 
population will double every 50 years (Cahaner \& Malach, 2020). The rapid demographic growth of the Haredi population increases its economic, social, and political standing, thus attracting public, media and political attention.

Haredi Jews form a closed society whose leadership developed defenses against the "prying" secular society (Lehmann, 2010). Haredi Jews engage in voluntary, self-imposed "hiding" of information and knowledge as a means to conserve the community, striving to retain its traditions and sustainability (Yitzhaki, 2020). Haredi Judaism views Torah study as the purpose of creation. In Israel the Haredi educational system discourages general education in favor of immersion in studying Torah and Talmud, and personal piety. Men are expected to engage in full-time Torah study through adulthood, and women, to become mothers, wives, and breadwinners in order to support their husbands' Torah study (Finkelman, 2011). The Israeli society faces civil challenges that polarize the Haredi Jews, from the secular society, such as: exemption of Haredim from mandatory military service, allocation of stipends to the Haredim enabling them to support their families while studying Torah, subsidized housing and a unique education system that accommodates their view (Shapiro, 2013). The internet is viewed with suspicion, as many Haredim express fear that its use represents a serious threat to their group's norms and its hierarchy of authority (Campbell, 2011).

While the Israeli secular society is individualistic, the Haredi society is a collectivist society with the rabbi playing an important part in routine and non-routine decisions. Members of this minority will not make a decision without the consent of the scholarly leader of the community, referred to as the "Rebbe" (Band-Winterstein, \& Tuito, 2018). The Haredim seek the consent of the rabbi and accept that everyday decisions and all changes in the private and the public domains need rabbinic approval (Fass \& Lazar, 2011). Changes are made only within the limits of the consensus, without breaching conventions and without contradicting the society's norms and values (Stadler, 2007). Haredi fathers have great power over decisions of their children (Finzi-Dottan \& Gilerenter, 2018).

Torah study is a central pillar of the Haredi minority (Lehman \& Siebzehner, 2009). The Haredi culture embodies values of devotional study, modesty, family stability, personal responsibility, and mutual assistance. The ideal is a complete devotion to Torah studies, with a clear sense of identity and social security. This minority feels that it has established an ideal society, superior to secular society (Friedman, 1991). Israel is a welfare state which assumes responsibility for education, for health through a national health system, and for the income maintenance of all its citizens, including its minorities (Friedman, 1991). However, within this minority there are various segments who feel so estranged from state institutions that they even refuse to accept services from it. A number of Haredi streams in Israel oppose Zionism and don't recognize the State of Israel. They refuse all funding from the Israeli state and abstain from taking part in the political process. (Kimmerling, 1989). There are Haredi groups, that oppose secular Zionism but do recognize Israel. They vote in elections and accept state funding. There is a growing group of Orthodox Jews known as Hardalim, who moved in their religious observances towards Haredi Judaism. According to a 2016 Pew survey, 33\% of Israeli Haredim say that the term "Zionist" describes 
them accurately (Sasson et al., 2017). The Lithuanian stream, to which respondents belong, participate in national elections and send their representatives to the Israeli parliament. They adamantly oppose to serving in the military because they see learning Torah as more worthwhile. Overtime, however, they have shifted to be supportive of the state of Israel, although not officially recognizing itself as a pro-Zionist. They are represented in the Israeli parliament and try to influence a pro-Judaism outlook, focusing mainly on funding for Jewish education (yeshivas), exemption from military service for Haredi yeshiva students, and further strengthening Israel's Jewish identity (Kimmerling, 1989).

The Haredi minority as a whole lives as an "enclaved culture" in a surrounding modern environment that it perceives as threatening its existence (D'Antonio \& Aldous, 1983). One of the main conflicts in this minority is whether and to what extent to open up to the surrounding environment and its influences. To protect their culture, this minority seeks to maintain its traditional way of life and builds a virtual "protective wall", a "wall of virtues", based on values that it perceives as a common and worthy good, while extending religious polarization (D'Antonio \& Aldous, 1983; Kalagy, 2016). One pressing dilemma of this enclaved society is the attitude towards the dissemination of modern values, such as education (Kalagy, 2016). Traditionally, this minority prohibited the use of the internet. The use of the internet and its platforms almost doubled from $28 \%$ in $2008-2009$ to $54 \%$ in $2018-2019$ due to the number of employed persons from the minority in the education sector, the rising number of Haredi students (particularly females), and the changes in the characteristics of the Haredi culture of leisure and consumption (Cahner \& Malach, 2020). Since March 2020, due to COVID-19 internet use in Haredi society has grown to $66 \%$ (Cahner \& Malach, 2020). Also, tablets and laptops were allocated to ultra-religious students by academic colleges and to school and yeshiva students by the Ministry of Education to enable long-distance learning through the ZOOM platform, particularly among disadvantaged populations such as the Haredim (Lev-On et al., 2020).

The Haredi minority's response to the threats of infection may stem from its hierarchical decision-making processes (Koyama \& Carvalho, 2011), its spatial attributes of living (Friedman, 1991), the struggle of its leaders to control the dissemination of information to community members (Stern, 2020), the clashes between social distancing and communal traditions (Donin, 2019; Pirutinsky et al., 2020, and the tensions and distrust between the health authorities and the community (Stern, 2020).

The Haredi relationship with the government and the state of Israel is complicated. Haredim are committed to the idea that Jewish sovereignty in a state of one's own is not a positive thing and only with the coming of the messiah will God bring all the Jews to the land of Israel and allow them to rule themselves under religious law. Haredim maintain that Israel can only be regained miraculously viewing the present state of Israel as a blasphemous human attempt to usurp God's role. The religious grounds of anti-Zionism is that today's Zionism is a secular Zionism, packed with non-Jewish influences, and lacking key features like Mashiach and the rebuilt Temple. Religious works and Torah study will save the people and bring about Redemption (Friedman \& Dromi, 2005). 


\section{The Underground Home Hospitals}

The Haredi Jewish neighborhoods became home to UHHs which provide secret unsupervised medical care for more than 1000 Haredi COVID-19 patients, including those in critical condition, in six Haredi cities (Sherki, 2020; Doctors Only, 2020). Guidance to establish UHHs came from the Haredi community in the United States, where medical activists warned the Israeli community leadership that everything must be done so minority members will not reach the hospitals (Sherki, 2020). The patients' families insisted on home care and refused to evacuate their loved ones to any public hospital where they will be connected to a cannula, with no one to look after them, as physicians at the public hospitals claimed that there was a shortage in staff (Sherki, 2020). Since April 2020, equipment was purchased from abroad and the UHHs were established to avoid hospitalizations in public hospitals. The operation was led by a Haredi NGO called 'Hasdei Amram' which purchases the equipment. This operation is beyond the regular interface of Haredim with healthcare which entails referrals to doctors, financing medications, support, and food and clothes and extends to providing medical care to patients in UHHs while secretly employing religious expert physicians to provide care with the assistance of volunteers who were trained for this purpose.

The UHHs were exposed by chance and reported on through the mass media. The coverage showed a basement set up with respirators, all the required equipment, medical devices, and medications. Participating clinicians are male only: emergency doctors and nurses in 12-h shifts, who visit patients at least 3-4 times a day depending on the severity of the disease and a physiotherapist who visits each patient twice a day to activate the patient's respiratory system. Volunteers prepare devices (e.g., oxygen reservoirs at the concentration required) check vital signs, perform electrocardiograms, give medications, provide $24 \mathrm{~h}$ patient monitoring, and transport equipment among patients. They accompany the clinicians during each visit and drive them between patients, provide respiratory physiotherapy by clapping on the lungs, and deliver blood tests to laboratories on a daily basis. However, the condition of COVID-19 patients who are not monitored in intensive care can deteriorate very rapidly. The fact that there is a COVID-19 patient at home was not reported to the authorities, as the patient was never tested for COVID-19 in a healthcare facility to avoid becoming known to the authorities (Sherki, 2020).

\section{The Current Study}

Although qualitative studies may greatly contribute to understanding the lived experiences of communities in medical emergencies, most studies on medical emergencies are quantitative (Vindrola-Padros et al., 2020). This thematic study explores the lived experiences of Haredi Jewish patients, including community leaders, in UHHs. Interviews were conducted in Israel during the second wave of the pandemic, from September to November 2020. This study extends the knowledge on compliance of minorities in a health crisis to community directives that contradict national 
directives regarding hospitalization through the framework of patient-centered care. Research on the conduct of religious minorities in a multi-cultural world during a pandemic is timely and relevant. The research questions are: What are the lived experience and perceptions regarding the UHH, religion, and health among members of the religious minority? What underlies their harnessing of the UHH?

\section{Materials and Methods}

\section{Procedure and Sampling}

The Haredim account for only $12.6 \%$ of the population. The UHH started among the Lithuanians, which are a sub-group in Haredi Judaism accounting for $32 \%$ of the population and includes Ashkenazi Haredim who are not Hasidim or members of the extremist "Jerusalem Faction" (Regev \& Gordon, 2020). The Lithuanians traditionally oppose the Hasidic sects (Kreuser, 2012). Study participants are Lithuanians, a rare sector accounting for $4 \%$ of the Israeli population. Secular people arouse suspicion, making it difficult to access minority members. Since UHHs constitute unlawful activity, they present a highly sensitive issue of breaching national directives, employing physicians who risk losing their license. Minority members are not only a rare population but also a hidden population, as both patients and clinicians are reluctant to co-operate and intentionally avoid exposure (Spreen, 1992; Watters \& Biernacki, 1989). Thus, our research challenge pertained mostly to data accessibility and reliability (Cohen \& Arieli, 2011; Goodhand, 2000). Using standard sampling methods with rare and hidden populations yields a high rate of nonresponse, requiring methodologies and appropriate sampling techniques (Gabay \& Shafran-Tikva, 2020; Salganik \& Heckathorn, 2004). We used an adaptive-sampling design selection procedure (Thompson \& Frank, 2000). Through previous studies that the second author, a secular male Muslim, we gained the trust of a Lithuanian rabbi, who served as a moderator, with whom we collaborated to plan the study and create willingness of community members to participate (Spreen, 1992). The rabbimoderator's role, in addition, was to make the connection between the researcher and the participants and to give his blessing to their participation. Interviews were conducted in Hebrew with community member volunteers who had access to a computer. Several respondents referred each of us to another interviewee whose health was improving and who agreed to share his lived experiences. Clinicians refused to participate, perhaps for fear of jeopardizing their medical license.

Participants were 30 patients ages 59-78, with a mean age of 69 and an average of 9 children. Table 1 presents the sample demographics. The second author created a link, sent it to the volunteer, and in time, performed a non-recorded interview with an open camera, over a ZOOM platform, without knowing the interviewee' family name or contact information. We employed the respondent-driven sampling method until the desired sample size was reached (Salganik \& Heckathorn, 2004). We determined the study sample size using the information saturation approach (Saunders et al., 2018). 
Table 1 Sample demographics

\begin{tabular}{|c|c|}
\hline Age & \# Children \\
\hline 65 & 7 \\
\hline 59 & 8 \\
\hline 68 & 7 \\
\hline 66 & 7 \\
\hline 63 & 8 \\
\hline 64 & 9 \\
\hline 67 & 9 \\
\hline 69 & 8 \\
\hline 68 & 10 \\
\hline 67 & 11 \\
\hline 64 & 9 \\
\hline 66 & 10 \\
\hline 69 & 10 \\
\hline 68 & 9 \\
\hline 67 & 9 \\
\hline 66 & 10 \\
\hline 63 & 8 \\
\hline 65 & 9 \\
\hline 64 & 8 \\
\hline 74 & 12 \\
\hline 67 & 8 \\
\hline 76 & 11 \\
\hline 74 & 9 \\
\hline 78 & 10 \\
\hline 76 & 9 \\
\hline 74 & 8 \\
\hline 74 & 9 \\
\hline 75 & 11 \\
\hline 76 & 9 \\
\hline 78 & 10 \\
\hline Mean age 69 & Mean 9 \# Children \\
\hline
\end{tabular}

\section{Ethical Approval}

The ethics committee at the academic institution with which the second author is affiliated granted ethical approval for this study $(\# 2,020,220)$. Patients signed an informed-consent form that meets ethical requirements regarding both participation and publication. A moderator from the Haredi community transferred the form to interviewees. After the form was signed, the interviews began, according to the schedule suggested by the interviewees and the moderator. To protect anonymity and confidentiality, additional demographic attributes of the participants are omitted, and sample data is presented only at the group level (Morse, 2007). The 
informed-consent form described the ZOOM interview format stated that the interview would not be recorded, that participation is anonymous and confidential, and that the participant may stop the interview at any stage.

\section{Quality Criteria}

We maintained the general quality standards of qualitative research (Guba \& Lincoln, 1994) and acknowledged our privileged position as secular academic researchers who understand the intercultural tensions and have a relationship of mutual trust with our contacts in the Haredi community. To ensure that our findings are relevant and actionable, we collected data in real time rather than retrospectively, i.e., while the UHHs are still operating. To support the transferability of the findings, we provided dense descriptions of the points of view of interviewees. To preserve meaning and nuances, translation from Hebrew to English was performed by a religious English-speaking professional editor following data analysis. To assure reliability, the authors analyzed all interviews independently and identified themes and subthemes in the data. The interviews' content was anchored within three contexts that may have affected it: the broad context, the micro-context, and the immediate context (Josselson, 2013; Kupferberg, 2010). The broad context was the political tension and distrust between the Haredi minority and the government and its authorities. The micro-context was the need to justify and rationalize the unlawful activity. The immediate context of the "here and now" may have also affected the narrative: our neutral academic identity as the audience for their story and their agreement to participate in the study. The narrative is the story each interviewee chose to share rather than everything that is happening to them (Hewitt, 2007).

\section{Data Analysis}

Thematic analysis guided data analysis of the interviews (Aronson (1992) aimed at exploring experiences of patients. Themes are units derived from patterns, such as recurring meanings, feelings, and perceptions (Taylor \& Bogdan, 1984). We identified themes by bringing together elements of ideas or experiences, which often, when viewed alone, are meaningless but make sense in a specific context as they emerge from the data (Leininger, 1985). We identified themes and patterns of experiences and perceptions that emerged from the data through six analytical steps: (1) We independently read and re-read the interviews and listed patterns of experiences and perceptions through direct quotes. (2) We identified all data that related to the already classified patterns. (3) We placed all data of a specific pattern with the corresponding pattern. (4) We combined related patterns and categorized them into sub-themes to obtain a comprehensive view of the patterns that emerged regarding non-compliance, trust in the health authorities, perceived risks, self-perception, and perceptions of the surrounding society. We then pieced together themes in a meaningful way to form a comprehensive picture representing patients' interpretation of their experiences (Leininger, 1985). 6. By referring back to the theory of religious polarization, we gained information that allowed us to make inferences from the 
interviews regarding religious polarization and non-compliance with health policies during a crisis (Constas, 1992).

\section{Findings}

Findings present the perceived experience of self-isolation of hospitalization in public hospitals, community beliefs and directives, perceptions of clinicians at public hospitals, traditions in public hospitals versus traditions in UHHs, perception of the health authorities, perception of the secular majority, self-perception, perception of clinicians working at UHHs, and issues related to a collectivistic culture.

\section{Perceived Experiences of Patients in COVID-19 Wards at Public Hospitals}

Participants perceive the hospitalization experience in COVID-19 wards at public hospitals as alienating, self-isolating, lonely, and fearful:

These are wards of loneliness, of quiet... of speedy death. Haredi family members cannot even say goodbye to their relatives. There is no human touch in such deaths, no closeness to the Torah." (19);"The doctors and nurses wear opaque suits that look like space suits. Patients see nothing but eye movement. It is frightening." (1); "The ward looks like a scene from a horror movie, figures in white move about silently. Really horrible." (2); "You remain isolated with yourself in agony." (3); "A patient's wife said her husband looked frightened, could barely complete a sentence, needed resuscitation and within an hour, she was informed that he had died" (15).

Participants also described what they heard about the ward's environment:

Doctors and nurses talk through a loudspeaker, standing behind a glass window, take a quick look at the room and at the monitors and that's it." (11); "People are dying from loneliness and anxiety attacks, they are alone and frightened." (6); "There is terrible heat, no air conditioner, if there is, it is operated to prevent the spread of the disease to clinicians. The smell of sweat dominates, the heavy breathing of patients around you, the silence, you only hear the sounds of the respirator and monitors, the fatigue, the fear, the tears, the loss and death around you every day" (27).

\section{Perceptions of Clinicians at Public Hospitals}

Participants explicitly expressed distrust in clinicians working at public hospitals due to their lack of experience, their work overload, and the continuing lack of resources:

Clinicians are like the angels of death". (9); "I don't trust doctors in the hospital, their workload hurts us." (12); "The clinicians cannot breathe, they come out after four hours in the ward wet from head to toe, hoarse and dizzy due to the prolonged lack of oxygen in the suit. How can they treat patients prop- 
erly?" (2); "Clinicians treating COVID are inexperienced in treating COVID patients." (17); "Nurses take a crash course and then work in COVID-19 wards" (29).

\section{Public Hospitals and Traditions During COVID-19}

Participants described hospitalization in public hospitals as threatening community preservation and contradicting traditions:

"In the public hospital not only are we away from the Torah and the rabbi's blessings, but nurses and doctors don't know how to handle the bodies of religious patients who died of COVID. Do they know how to inform a family that it needs to say goodbye? How can they bury religious people according to Jewish law?" (24); "This is a disaster! Dying with no farewell and without prayers for the dead!" (2);"I prefer to die near my rabbi in my home among the Torah scrolls, not in the hospital. I want to die according to the rabbinic laws, not the laws of the state" (4).

\section{Underground Home Hospitals and Tradition During COVID-19}

Participants related to the strong connection between home hospitalization and the ability to keep up their Torah studies and maintain traditions:

"It is more important that the synagogues continue to operate than to abide by the government's severe restrictions. Synagogues and study are the core of our religious existence. We have values of moral religious importance. We uphold the physical existence of the world. If synagogues close and Torah study stops, the world will collapse and disappear." (5); "Prevention of the plague is only through prayer and continuing Torah study " (8); We believe that our people will heal at home, through Torah studies and blessings from the rabbis" (1).

Participants related to sustaining values in an inter-generational manner:

"We need to ensure that our grandparents are not alone in this disease." (3); "Not only do we care for our followers but we keep them closer to other community members who maintain Torah studies. This is the mission we received from our rabbis." (15); "We are not afraid of COVID; we are only afraid of God." (12); "When a 16-year-old granddaughter and a 17-year-old grandson are by their grandparent's bed, for three weeks from morning to evening, feeding them, engaging with them, they assimilate values that pass down from generation to generation" (14).

\section{Perception of the Health Authorities}

Participants told of their distrust in health authorities and their belief that the government is against them: 
I was surprised that the Ministry of Health said it was unfamiliar with the phenomenon. After all, they see those large numbers of blood tests coming from the Haredi neighborhoods, and they see that there are hardly any people from our population in hospitals. I thought they turned a blind eye. But did they really not know?" (2); "Public hospitals will oppose our activity because for every COVID patient, the government pays them a lot of money." (6); "The government is trying to keep religious people away from God, we will not listen." (16); "The politicians who talk badly about us will not get up at night to help others, they only get up at night for interviews to strengthen their public image." (12); We don't believe in the government, or its authorities because they treat us fairly. We are viewed as primitive, as parasites." (19); "We function separately from the world around us, an "enclaved culture"—a society that seeks to zealously maintain a distance from the general society." (8); "We oppose all guidelines that keep us away from Torah study and synagogues." (25): "A person is autonomous over his body and has the right to decide where to be hospitalized" (4).

Participants expressed their expectations of the government and health authorities and justified the UHH as reflecting their values and beliefs in patient-centered care:

They call it an underground hospital but it's just a home hospital that is actually a great method for dealing with this epidemic: patients are satisfied with the care, it reduces hospital overflow, it's a win-win situation but they will kill the method just because we invented it." (14);"Instead of the government and police that is killing our religious community and our rabbis, they should listen to the rabbis and learn how to deal with a plague, not just when they need a blessing for the elections." (8); "Public hospitals can only learn from us and adopt our model of providing COVID care in the community, not just idle talk and long procedures... They are supposed to help us and not eliminate us... [Quiet].

\section{Perception of the Secular Majority}

"At first the secular were angry at us, because we disrespect the guidelines. Whoever disregards science and medicine in this country is viewed as primitive. Then, suddenly, they see that maybe there is something beyond those misperceptions, something that makes sense." (1); "Perhaps the secular now understand that we understand everything but do not want to be distanced from our community and our great Torah. Being enveloped by human contact without anxiety attacks is care that saves lives." (4); "The story of the "underground" hospital reflects the headlines and the noise that the government has been making around us" (21); "To call this a "State within a State" is to take a great thing and present it in a negative, ugly light. We did not steal or receive money; we only help." (13); "They should appreciate how we risk our lives for others. They call us "Violators of the law," "fanatics", instead of praising our youth who visits patients four times a day on the high holidays but the goal 
is to attack us." (11);"If the Haredim are egotists and parasites, why is it so important to them to get up at 3:00 A.M. and drive an hour to replace an oxygen tank? For the sake of politics, no one makes such an effort"(2).

\section{Self-Perception: We Are Better Than Them}

"Our rabbi was infected with COVID, he was treated in an underground hospital and recovered. He is 93 years old! He symbolizes modesty and compassion, the love of Torah, he is an example to the whole world." (9); "Congratulations to us for the "mitzvah", the mutual guarantee and care for the sick... a good and genuine desire to help the other. We envy others who help more. I am jealous of my Haredi brothers for their ability to provide caring around the clock, distribute oxygen tanks and food day and night, even during the holidays without sleep at night.";(4) "I hope that we are inspiring people to understand is that it is their duty to visit their loved ones in COVID wards. It greatly encourages the ill to survive." (11);"We have pure intentions to help others. They sow hatred and conflict but we Haredim help others without thinking twice, no matter who needs help, day or night." (30); "This is extraordinary volunteerism of our people that provides dedicated personal care, rather than throwing people into the death industry, detached from rabbis, family, children, synagogues, and friends." (21); "I keep reciting to myself a song written by Hannah Senesh, from October 11, 1940. It is a wonderful song about man's search for humanity, within the war. It is a plea that even in this total darkness, we will find a spark of light. It represents our righteous rabbis." (16).

\section{Perception of Clinicians at the Home Underground Hospitals}

The clinicians are perceived as enabling patients to stay within their family, close to the Torah, and as the best doctors in the country who made the right choices:

The nurses sit with us for 30-45 min, talk, pay attention to us so we are confident that they are by our side for anything we need" (3); "Our rabbis recruited some of the best pulmonary doctors in the country and nurses from intensive care units, they are all religious." (28); "We have the best medical teams with a lot of experience in respiratory intensive care, respirator technicians, and all the experts in the field." (30); "Today I feel a great improvement. I know the clinicians are walking a thin line between the ward at the hospital that needs them. They have no interest in the legal issues. They are doctors treating patients and by working here, they are actually helping to prevent the overflow in hospitals." (6); "They, too, know that when patients are far from their family, isolated, it makes things worse. The soup, the sounds of the children, the proximity to the synagogue, the blessings from the rabbis on high holidays are a cure. They know we prefer to die at home rather than at the hospital. We do not reveal their names, "he who saves one soul from Israel it is as if he saved the entire world." (2)."The doctors and nurses and the physiotherapist always 
read a prayer before any treatment. They are not just doctors; they are angels who care for the sick." (16).

\section{Collectivism}

Participants related to the community, and to the rabbi's guidelines as their paramount influence:

We listen to the laws of the 'Halakhah', not the laws of the state." (7);"We prefer that all guidelines come only through our rabbis and not through the health authorities or politicians. When the government forces us to close the synagogues, our leaders understand that there is no choice but to disobey." (22); "Family, food, conversation, education, the human touch, are all critical to beating this virus "(16); "We will always follow the rabbi, not the laws of the state or the doctor." (2);"I only listen to my Rabbi and receive instructions only from him. Thanks to his prayers I recovered " (10).

\section{Discussion}

This thematic study explored the lived experiences of Haredim, members of a religious minority and their compliance with community directives rather than with the national directive requiring hospitalization of COVID-19 patients in solitude at public hospitals. Since the outbreak of the second wave of the COVID-19 pandemic in Israel, the Haredim refused to be hospitalized in COVID-19 wards in public hospitals and harnessed UHHs in the community, according to the patient-centered care approach which is a desired approach of care but far from achieved approach at public hospitals (Stadler, 2007). UHHs not only provided patient-tailored care but also demonstrated the way the Haredim prevented damage to their values despite the COVID-19 circumstances (i.e., lack of traditional death rituals) (Kalgay, 2016). To protect their culture, this minority established a vast operation that serves as a "protective wall" enabling them to maintain their religious values and respect each patient's psychological needs.

Hospitalization at public hospitals in grief and solitude conflicts with fundamental values of the Haredim, who value social and emotional support from the rabbi, community, and family. Cases of sudden death, with complex grieving processes, filled the leadership with guilt as the corpse was taken directly to burial, leaving mourners with a feeling of not paying respect to their loved ones and contravening tradition and God's commandment. Supporting previous studies, self-isolation of community members while being treated at the public hospital separated them from the community at a time of extreme crisis, creating a sense of anomie (Dein, 2020). Hospitalization in public hospitals was perceived as robbing the Haredim of proper religious rituals, stripping the dead of their dignity, and exacerbating the grief of the living (Fernández \& González-González, 2020). The impossibility of maintaining long-standing Jewish traditions was a trigger for leaders of this minority to conceive and establish unlawful UHHs without any qualms. Findings suggest 
that while responses to epidemics in secular societies are linked with modernization, state-building, and the establishment of medical institutions, responses of religious minorities to epidemics are linked to intergenerational traditions, beliefs, and values (Lehmann, 2013; Ripoll, 2020).

The UHHs strengthened beliefs such as "silver lining" reappraisal, tolerance of uncertainty, and a sense of purpose" (Pirutinsky et al., 2020). Findings stress that the UHHs accord with the desire to provide religious people with PCC even during a crisis. PCC that this minority adopted served as a mechanism for both selfpreservation and community preservation. Support through the UHH went beyond the usual support of providing food, social support, and prayer support (WeinbergerLitman et al., 2020). UHH extended the traditional support of the community to its members to PCC, entailing physical and emotional care in severe illness, proof that despite the challenges, PCC can be achieved even during a health crisis Patients specifically mentioned that clinicians recited prayers before administering treatment, reflecting their shared religious observance, reflecting PCC as considering patient beliefs and preferences. The belief in PCC may have enabled them to collaborate with the community (Schmidt \& Roffler, 2020). Findings support previous studies on religious coping and spiritual health as reducing death anxiety among the elderly during COVID-19, and faith as key to resilience in a crisis (Pirutinsky et al., 2020; Solaimanizadeh et al., 2020.

As the global society is becoming religiously fragmented, health authorities must consider and accommodate religious and spiritual needs of minority members regarding COVID-19 hospitalizations (Gad et al, 2020). Denying religious minorities their rights to conduct traditions in a safe manner reduces compliance and fuels unlawful behaviors. Distrust in the health authorities may be exacerbated during a pandemic, creating a counter-response by the minority to preserve their values. Thus, health policies and directives during a pandemic cannot be optimized among religious minorities through coercion (Ripoll, 2020). Coercing compliance will deepen resistance, particularly when members of religious minorities feel that such compliance contravenes their duty towards God, family members, ancestors, beliefs, values and the approach of care that accords those. This study stresses the need to implement multi-cultural measures and differential ways to provide care among religious minorities, supporting the acknowledged multi-cultural approach in healthcare and patient-centered care (Betancourt et al., 2016; Woskie \& Fallah, 2019).

\section{Implications for Practice}

Responses of health authorities to the pandemic and national directives forcing public hospitalization may not have considered the social challenges that health policies and directives raise among minority groups. Policymakers are called upon to explore ways to provide PCC across population and enable religious minorities to adhere to their values and continue traditional religious practices. Health authorities are called upon to denounce politicization of the responses to the COVID-19 epidemic and to enhance trust in health authorities through the understanding of cultural diversity. The collaboration of healthcare professionals with leaders of the 
religious communities is needed to ensure a holistic understanding of religion, compliance, and health (Hashmi et al., 2020).

Thus, health authorities are further urged to explore a multi-cultural strategy rather than one strategy for all. Religious leaders influence the social values, practices, and beliefs of their community members and can contribute in designing multi-cultural health policies (Weinberger-Litman et al., 2020). We call upon health authorities to hold participatory dialogues with leaders and representatives of minority religion communities. Health authorities are called upon to consider an adaptive strategy formulated in collaboration with engaged leaders of each religious minority to accommodate PCC as well as cultural traditions, community beliefs, perceived duties, values, and health.

An adaptive strategy may entail: Appealing directly to leadership of religious minorities; understanding needs, beliefs and directives of the community, establishing centers for monitoring COVID-19 in neighborhoods of religious minorities manned by local staff; communicating risks only through their leadership; and learning from the Haredim about home hospitalization and the implementation of PCC for COVID-19 patients. These actions may alleviate tensions between the religious minority and the government, the health authorities, particularly if minority religious groups do not have to defend their symbolic context (Poleykett, 2018).

\section{Limitations}

Interviews were conducted at a single point in time during the crisis, and it is yet to be seen how the UHHs develop and what their implications and consequences will ultimately be. Also, participants were only men, who are the one who make decisions in religious minorities, and they may not reflect the view of Haredi women.

\section{Conclusion}

Hospitalization at public hospitals in an atmosphere of grief and solitude conflicts with fundamental values of the Haredim, robbing them of proper religious rituals and exacerbating the grief of survivors. A one-strategy-for-all may not consider the social challenges that health policies and directives raise among minority groups. UHHs provided PCC to Haredim in severe illness, enabled self-preservation, and maintained long-standing Jewish traditions during the pandemic as an alternative to public hospitalization. Health authorities are called upon to consider and accommodate the religious and spiritual needs of minority members regarding COVID-19 hospitalizations. Denying religious minorities their rights to conduct traditions in a safe manner breaches trust, reduces compliance, and fuels unlawful behaviors. An adaptive strategy, formulated in collaboration with engaged leaders of each religious minority, may accommodate PCC, cultural traditions, community beliefs, perceived duties, values, and health. There may, indeed, be unbridgeable divides inhibiting the translation of religious traditions into public health policies, but the sincere attempt 
to create collaborative multi-cultural health policies during pandemics must be an essential component of the political process of shaping such policies.

Acknowledgements Our sincere thanks to the moderators and participants for their contributions.

Funding No funding was received.

\section{Declarations}

Conflict of interest The authors declare that they have no conflict of interest.

Ethical Approval All procedures performed in this study, involving human participants, were in accordance with the ethical standards of the institutional research committee and with the 1964 Helsinki Declaration and its later amendments or comparable ethical standards. The study was approved by the Bioethics Committee of the Academic College of Tel Aviv -Jaffa (No. \# 2020220).

Human and Animal Rights This article does not contain any studies with animals performed by any of the.

\section{References}

Algan, Y., Malgouyres, C., \& Senik, C. (2020). Territories, well-being and public policy. Notes Du Conseil D’analyse Économique, 55(1), 1-12. https://doi.org/10.3917/ncae.055.0001

Allcott, H., Boxell, L., Conway, J., Gentzkow, M., Thaler, M. \& Yang, D. Y. (2020). Polarization and public health: Partisan differences in social distancing during the Coronavirus pandemic, NBER Working Paper (w26946). Available at SSRN: https://ssrn.com/abstract=3574415

Aronson, J. (1992). The interface of family therapy and a juvenile arbitration and mediation program. Unpublished doctoral dissertation, Nova Southeastern University, Fort Lauderdale, FL., U.S.A.

Band-Winterstein, T., \& Tuito, I. (2018). The meaning of choosing a spouse among ultra-Orthodox Jewish women who found themselves in a violent relationship. Violence against Women, 24(6), 727744. https://doi.org/10.1177/1077801217722236

Bargain, O. \& Aminjonov, U. (2020). Trust and Compliance to Public Health Policies in Times of COVID-19. Available at SSRN: https://ssrn.com/abstract=3596671

Betancourt, J. R., Green, A. R., Carrillo, J. E., \& Ananeh-Firempong, I. I. (2016). Defining cultural competence: A practical framework for addressing racial/ethnic disparities in health and health care. Public health reports. https://doi.org/10.1093/phr/118.4.293

Behadrei Hadarim. Retrieved on Feb 2nd at https://www.bhol.co.il/news/1145289 (Hebrew)

Behadrei Hadarim. Retrieved on Feb 2nd at https://www.bhol.co.il/news/1145289.

Cahaner, L. and Malach, G (2020). Statistical report on Ultra-Orthodox Society in Israel. The Israeli institute for Democracy. [Hebrew]

Campbell, H. (2011). Religion and the Internet in the Israeli Orthodox context. Israel Affairs, 17(3), 364383. https://doi.org/10.1080/13537121.2011.584664

Chaudhry, R., Dranitsaris, G., Mubashir, T., Bartoszko, J., \& Riazi, S. (2020). A country level analysis measuring the impact of government actions, country preparedness and socioeconomic factors on COVID-19 mortality and related health outcomes. EClinicalMedicine, 25, 100464. https://doi.org/ 10.1016/j.eclinm.2020.100464

Cheah, J. (2001). Chronic disease management: A Singapore perspective. BMJ, 323, 990-993.

Cohen, N., \& Arieli, T. (2011). Field research in conflict environments: Methodological challenges and snowball sampling. Journal of Peace Research, 48(4), 423-435. https://doi.org/10.1177/00223 43311405698

Cohen, A. B., \& Hill, P. C. (2007). Religion as culture: Religious individualism and collectivism among American Catholics, Jews, and Protestants. Journal of Personality, 75(4), 709-742. https://doi.org/ 10.1111/j.1467-6494.2007.00454.x 
Constas, M. A. (1992). Qualitative analysis as a public event: The documentation of category development procedures. American Educational Research Journal, 29(2), 253-266. https://doi.org/10.3102/ 00028312029002253

D’Antonio, W. V., \& Aldous, J. (Eds.). (1983). Families and religions: Conflict and change in modern society. SAGE Publications.

Dein, S. (2020). Covid-19 and the Apocalypse: Religious and Secular Perspectives. Journal of Religion and Health. https://doi.org/10.1007/s10943-020-01100-w

Delaney, L. J. (2018). Patient-centered care as an approach to improving health care in Australia. Collegian, 25(1), 119-123. https://doi.org/10.1016/j.colegn.2017.02.005

Donin, H. (2019). To Be a Jew: A Guide to Jewish Observance in Contemporary Life Selected and Compiled from the Shulhan Arukh and Responsa Literature and Providing a Rationale for the Laws and the Traditions. Basic Books.

Durkheim, E. (1995). Elementary forms of religious life (trans K.E. Fields). Free Press.

Epstein, R. M., \& Street, R. L. (2011). The Values and Value of Patient-Centered Care. https://doi.org/10. 1370/afm. 1239

Fass, H., \& Lazar, R. (2011). Social work and the Haredi community in Israel: From rejection to acceptance as reflected in narrative of a Haredi social worker. Reflections, 17, 32-37.

Fernández, Ó., \& González-González, M. (2020). The Dead with No Wake, Grieving with No Closure: Illness and Death in the Days of Coronavirus in Spain. Journal of Religion and Health. https://doi. org/10.1007/s10943-020-01078-5

Finkelman, Y. (2011). Ultra-orthodox/Haredi education. In H. Miller, L. Grant, \& A. Pomson (Eds.), International handbook of jewish education international handbooks of religion and education. Springer.

Finzi-Dottan, R., \& Gilerenter, N. (2018). Ultra-Orthodox Jewish fathers in Israel: Predictors of involvement and acceptance. Journal of Family Issues, 39(10), 2735-2756. https://doi.org/10.1177/01925 $13 \mathrm{X} 18761118$

Friedman, M. (1991). The Haredi (ultra-Orthodox) society -sources, trends and processes. The Jerusalem Institute for Israel Studies, Jerusalem, Israel. pp.3-10.

Friedman, M., \& Dromi, U. (2005). These are the Chronicles of the Status-Quo: Religion and State in Israel. Brethren Dwelling Together. Orthodoxy and Non-Orthodoxy in Israel: Positions, Propositions and Accords, 57-89).

Gabay, G., \& Shafran-Tikva, S. (2020). Sexual harassment of nurses by patients and missed nursing care-A hidden population study. Journal of Nursing Management, 28(8), 1881-1887. https://doi. org/10.1111/jonm.12976

Gad, I., Tan, X. W. C., Williams, S., et al. (2020). The Religious and Spiritual Needs of Patients in the Hospital Setting Do Not Depend on Patient Level of Religious/Spiritual Observance and Should be Initiated by Healthcare Providers. Journal of Religion and Health. https://doi.org/10.1007/ s10943-020-01103-7

Goodhand, J. (2000). Research in conflict zones: Ethics and accountability. Forced Migration Review, $8(4), 12-16$.

Guba, E. G., \& Lincoln, Y. S. (1994). Competing paradigms in qualitative research. Handbook of Qualitative Research, 2(163-194), 105.

Hashmi, F. K., Iqbal, Q., Haque, N., \& Saleem, F. (2020). Religious cliché and stigma: A brief response to overlooked barriers in COVID-19 management. Journal of Religion and Health, 59(6), 26972700. https://doi.org/10.1007/s10943-020-01063-y

Herman, T. \& Orr, A. (2020). The trust crisis, The Israeli institute for Democracy. Retrieved on Nov. 25, 2020. https://www.idi.org.il/articles/32008.

Hewitt, J. (2007). Ethical components of researcher-researched relationships in qualitative interviewing. Qualitative Health Research, 17(8), 1149-1159. https://doi.org/10.1177/1049732307308305

Jarrar, M. T., Minai, M. S., Al-Bsheish, M., Meri, A., \& Jaber, M. (2019). Hospital nurse shift length, patient-centered care, and the perceived quality and patient safety. The International Journal of Health Planning and Management, 34(1), e387-e396. https://doi.org/10.1002/hpm.2656

Josselson, R. (2013). Interviewing for qualitative inquiry: A relational approach. Guilford Press.

Kalagy, T. (2016). Three approaches to the connection between modernisation and traditionalism: A case study of the acquisition of academic education among ultra-Orthodox and Bedouin women. Culture and Religion, 17(3), 312-331. https://doi.org/10.1080/14755610.2016.1217898

Kimmerling, B. (Ed.). (1989). The Israeli state and society: Boundaries and frontiers. SUNY Press. 
Kitson, A., Conroy, T., Kuluski, K., Locock, L., \& Lyons, R. (2013). Reclaiming and redefining the Fundamentals of Care: Nursing's response to meeting patients' basic human needs. http://hdl.handle.net/2440/ 75843

Kitson, A., Marshall, A., Bassett, K., \& Zeitz, K. (2013b). What are the core elements of patient-centered care? A narrative review and synthesis of the literature from health policy, medicine and nursing. Journal of Advanced Nursing, 69(1), 4-15. https://doi.org/10.1111/j.1365-2648.2012.06064.x

Koyama, M., \& Carvalho, J. P. (2011). Development and Religious Polarization: The Emergence of Reform and Ultra-Orthodox Judaism. https://doi.org/10.2139/ssrn.1955232

Kreuser, A. (2012). The Haredi Sector Data. The Israeli Internet Association. [Hebrew]. Laufs, J., \& Waseem, Z. (2020). Policing in pandemics: A systematic review and best practices for police response to COVID-19. International journal of disaster risk reduction, 101812. https://doi.org/10.1016/j.ijdrr. 2020.101812

Kuluski, K., Peckham, A., Williams, A. P., \& Upshur, R. E. (2016). What gets in the way of person-centred care for people with multimorbidity? Lessons from Ontario. Canada. Healthc Q, 19(2), 17-23. https:// doi.org/10.12927/HCQ.2016.24694

Kupferberg, I. (2010). The Four Worlds Model for Interactive Discourse Analysis". In L. Kasen \& M. Cromer-Nevo (Eds.), Data Analysis in Qualitative Research (pp. 180-155). Ben-Gurion University of the Negev.

Laufs, J., \& Waseem, Z. (2020). Policing in pandemics: A systematic review and best practices for police response to COVID-19. International Journal of Disaster Risk Reduction, 101812.

Lehmann, D. (2010). Yeshiva fundamentalism: Piety, gender, and resistance in the Ultra-Orthodox world. Sociology of Religion, 71(4), 486-487. https://doi.org/10.1093/socrel/srq058

Lehmann, D. (2013). Religion as Heritage, Religion and Belief: Shifting Frontiers of Secularism in Europe, the USA and Brazil. International Sociology, 28(6), 645-662. https://doi.org/10.1177/0268580913 503894

Lehman, D., \& Siebzehner, B. (2009). Power, Boundaries, and Institutions: Marriage in Ultra-Orthodox Judaism, European Journal of Sociology; 50 (2); 273-308. https://www.jstor.org/stable/23999093

Leininger, M. M. (1985). Ethnography and ethno-nursing: Models and modes of qualitative data analysis. In M. M. Leininger (Ed.), Qualitative research methods in nursing (pp. 33-72).

Lev-On, A., Steinfeld, N., Abu-Kishk, H., \& Naim, S. P. (2020). The long-term effects of digital literacy programs for disadvantaged populations: analyzing participants' perceptions. Journal of Information, Communication and Ethics in Society.

Lusk, J. M., \& Fater, K. (2013, April). A concept analysis of patient-centered care. In Nursing forum, 48 (2), 89-98. DOI.org/https://doi.org/10.1111/nuf.12019.

Morse, J. M. (2007). Ethics in action: Ethical principles for doing qualitative health research. Qualitative Health Research. https://doi.org/10.1177/1049732307308197

Patel, J. A., Nielsen, F. B. H., Badiani, A. A., Assi, S., Unadkat, V. A., Patel, B., \& Wardle, H. (2020). Poverty, inequality, and COVID-19: The forgotten vulnerable. Public Health, 183, 110. https://doi.org/10. 1016/j.puhe.2020.05.006

Pirutinsky, S., Cherniak, A. D., \& Rosmarin, D. H. (2020). COVID-19, mental health, and religious coping among American Orthodox Jews. Journal of Religion and Health, 59(5), 2288-2301. https://doi.org/10. 1007/s10943-020-01070-z

Poleykett, B. (2018). Made in Denmark: Scientific mobilities and the place of pedagogy in Global Health. Global Public Health, 13(3), 276-287. https://doi.org/10.1080/17441692.2017.1414282

Rathert, C., Wyrwich, M. D., \& Boren, S. A. (2013). Patient-centered care and outcomes: A systematic review of the literature. Medical Care Research and Review, 70(4), 351-379. https://doi.org/10.1177/ 1077558712465774

Regev, E. and Gordon, G. (2020). The Haredim Housing market and Geographical Distribution of Israeli Hardei. The Israeli Institute for Democracy. [Hebrew]

Ripoll, S. (2020). Death and Funerary Practices in the Context of Epidemics: Upholding the Rights of Religious Minorities. https://doi.org/10.19088/CREID.2020.001

Ripoll, S. \& Jones, T. (2019). Health-Seeking Behaviors in Sofala and Manica in Relation to Cyclone Idai Response. Social Science in Humanitarian Action. Rapid Evidence Synthesis. www.socialsciencein action.org/resources/health-seekingbehaviours-sofala-manica-relation-cyclone-idai-response/ (accessed 23 September 2020).

Salganik, M. J., \& Heckathorn, D. D. (2004). Sampling and estimation in hidden populations using respondent-driven sampling. Sociological Methodology, 34(1), 193-240. https://doi.org/10.1111/j.0081-1750. 2004.00152-X 
Sasson, T., Aronson, J. K., Chertok, F., Kadushin, C., \& Saxe, L. (2017). Millennial children of intermarriage: Religious upbringing, identification, and behavior among children of Jewish and non-Jewish parents. Contemporary Jewry, 37(1), 99-123.

Saunders, B., Sim, J., Kingstone, T., Baker, S., Waterfield, J., Bartlam, B., \& Jinks, C. (2018). Saturation in qualitative research: Exploring its conceptualization and operationalization. Quality \& Quantity, 52(4), 1893-1907. https://doi.org/10.1007/s11135-017-0574-8

Schmidt, C., \& Roffler, M. (2020). Coping with the Practice of Medicine: Religion, Spirituality, and Other Personal Strategies. Journal of Religion and Health. https://doi.org/10.1007/s10943-020-01098-1

Shapiro S (2013) State and religion: the conflicts of Ultra-Orthodox Jews in Israel. PhD Thesis, Laurentian University of Sudbury, Sudbury. https://zone.biblio.laurentian.ca/handle/10219/2088

Sherki, Y. (2020). Revealed: Hundreds of ultra-Orthodox Corona patients treated in the underground. Behadrei Hadarim. Retrieved on October, 12, 2020. https://www.bhol.co.il/news/1145289 [Hebrew]

Solaimanizadeh, F., Mohammadinia, N., \& Solaimanizadeh, L. (2020). The relationship between spiritual health and religious coping with death anxiety in the elderly. Journal of Religion and Health, 59(4), 1925-1932. https://doi.org/10.1007/s10943-019-00906-7

Spreen, M. (1992). Rare populations, hidden populations, and link-tracing designs: What and why? Bulletin of Sociological Methodology/Bulletin de Methodologie Sociologique. https://doi.org/10.1177/07591 0639203600103

Stadler, N. (2007). Playing with sacred/corporeal identities: Yeshivah students' fantasies of military participation. Jewish Social Studies: History, Culture, Society, 13, 155-178. https://www.jstor.org/stable/ 4467769

Stern, S. (2020). The Dark Side of Communities: Illiberal Religious Communities' Compliance with COVID-19 Public Health Regulations. Available at SSRN 3637335.

Taylor, S. J., \& Bogdan, R. (1984). Introduction to qualitative research methods: The search for meanings. Wiley.

Thompson, S. K., \& Frank, O. (2000). Model-based estimation with link-tracing sampling designs. Survey Methodology, 26(1), 87-98.

Underground Hospitals. Doctors only press. Retrieved at https://publichealth.doctorsonly.co.i1/2020/10/ 208503/

van Dorn, A., Cooney, R. E., \& Sabin, M. L. (2020). COVID-19 exacerbating inequalities in the US. Lancet (london, England), 395(10232), 1243. https://doi.org/10.1016/S0140-6736(20)30893-X

Venhuizen, G. (2019). Can patient centred care plus shared decision making equal lower costs? BMJ. https:// doi.org/10.1136/bmj.15900

Vindrola-Padros, C., Chisnall, G., Cooper, S., Dowrick, A., Djellouli, N., Symmons, S. M., \& Johnson, G. A. (2020). Carrying out rapid qualitative research during a pandemic: emerging lessons from COVID-19. Qualitative Health Research. https://doi.org/10.1177/1049732320951526

Voshaar, M. J. H., Nota, I., van de Laar, M. A., \& Van Den Bemt, B. J. F. (2015). Patient-centred care in established rheumatoid arthritis. Best Practice \& Research Clinical Rheumatology, 29(4-5), 643-663. https://doi.org/10.1016/j.berh.2015.09.007

Watters, J. K., \& Biernacki, P. (1989). Targeted sampling: Options for the study of hidden populations. Social Problems, 36(4), 416-430.

Weinberger-Litman, S. L., Litman, L., Rosen, Z., Rosmarin, D. H., \& Rosenzweig, C. (2020). A look at the first quarantined community in the USA: Response of religious communal organizations and implications for public health during the COVID-19 pandemic. Journal of Religion and Health, 59(5), 22692282. https://doi.org/10.1007/s10943-020-01064-x

Wilkins-Laflamme, S. (2016). Protestant and Catholic Distinctions in Secularization. Journal of Contemporary Religion, 31(2), 165-1806. https://doi.org/10.1080/13537903.2016.1152660

Woskie, L. R., \& Fallah, M. P. (2019). Overcoming distrust to deliver universal health coverage: Lessons from Ebola. BMJ, 366, 15482. https://doi.org/10.1136/bmj.15482

Yitzhaki, M. (2020). Voluntary Information and knowledge "hiding" in a conservative community and its consequences: The case of the Ultra-Orthodox in Israel. In K. Arai, S. Kapoor, \& R. Bhatia (Eds.), Advances in Information and Communication Future of information and communication conference. Springer.

Publisher's Note Springer Nature remains neutral with regard to jurisdictional claims in published maps and institutional affiliations. 